\title{
Numerical modeling of radiation heat exchange in combustion chambers and heat exchangers of power installations
}

\author{
Nikolay Moskalenko, Ibragim Dodov and Azat Akhmetshin* \\ Kazan State Power Engineering University, 420066 Kazan, str. Krasnoselskaya 51, Russia
}

\begin{abstract}
The application of numerical modeling is considered to solve the problems of radiation heat exchange in structurally inhomogeneous two-phase media which are realized during the combustion of fuel in boiler units atmospheric emissions from air carriers when they move at supersonic speeds. The optically active ingredients of the gas phase of the combustion products have a sharp selection of spectral absorption lines (radiation) which causes a difference in the spectral transmission functions for selective radiation from the spectral transmission functions for non-selective radiation (gray body). In the presence of a dispersed phase of the combustion products acute selection is subjected to such a parameter of the radiation propagation medium as the probability of quantum survival. The number of spectral lines determining the spectral transmission functions increases with temperature and is determined by hundreds of thousands of lines at high temperatures. In this paper we consider a closed simulation of radiation heat transfer in combustion chambers when the temperature field in the combustion chambers is calculated first and then the flux of thermal radiation to the tube heat-receiving surfaces.
\end{abstract}

\section{Introduction}

In this paper, we consider the application of numerical modeling to solve the problems of radiation heat transfer in structurally inhomogeneous two-phase media, which are implemented during fuel combustion in boiler units, atmospheric emissions from aerial vehicles, when aerial vehicles move at supersonic speeds, during forest fires. Optically active ingredients of the gas phase of combustion products have a sharp selection of spectral absorption (radiation) lines, which causes a difference in the spectral transmission functions for selective radiation of the propagation medium from the spectral transmission functions for non-selective radiation sources (gray body). In the presence of a dispersed phase in a gaseous medium, such a parameter of the radiation propagation medium as "the probability of quantum survival" is subjected to acute selection. The number of spectral lines that determine the spectral transmission functions increases with increasing temperature and at high temperatures is determined by hundreds of thousands of lines. When solving problems of radiation heat transfer by the method of numerical simulation, it is necessary to know the parameters of spectral lines, intensities, half-widths, positions of centers, contours and their dependence on temperature. At high temperatures of combustion products $\mathrm{T}>2000 \mathrm{~K}$, it is necessary to take into account the nonequilibrium radiation, when the vibrational temperature of various ingredients differs from the gas-kinetic temperature. In connection with the cumbersomeness of numerical modeling of radiation heat transfer from the parameters of spectral lines, it is urgent to develop approximate calculation methods, when the parameters of the spectral transmission functions are from the data of an experiment performed at different temperatures on flame measuring complexes. In this work, a closed simulation of radiation heat transfer in combustion chambers is considered, when the temperature field in the combustion chambers is first calculated, and then the fluxes of thermal radiation onto the heat-sensing pipe surfaces

\section{Parameterization of radiation characteristics}

The main optically active components of the combustion products of hydrocarbon fuels are water vapor, carbon dioxide, $\mathrm{OH}, \mathrm{CO}$, nitrogen oxides $\mathrm{NO}, \mathrm{NO}_{2}$, the dispersed phase of combustion products, which is particles of soot and the mineral fraction of the burnt fuel. For the gas components of combustion products, the spectral transmission functions are calculated by the two-parameter method of equivalent masses [1-3], which makes it possible to solve the problems of radiation heat transfer in structurally inhomogeneous media. The spectral transmission functions $\tau_{\Delta v i}$ for component $i$ are determined from the relation,

$$
\left(\frac{1}{\ln \tau_{\Delta v i}}\right)^{2}=\left(\frac{1}{\ln \tau_{\Delta v i}^{\prime}}\right)^{2}+\left(\frac{1}{\ln \tau_{\Delta v i}^{\prime \prime}}\right)^{2}+\frac{M_{i}}{\ln \tau_{\Delta v i}^{\prime} \ln \tau_{\Delta v i}^{\prime \prime}}
$$


were

$$
\begin{aligned}
& \left|\ln \tau_{\Delta v i}^{\prime}\right|=\int_{L} k_{\Delta v i} F_{1}[L(T)] P_{i}(L) d L \\
& \left|\ln \tau_{\Delta v i}^{\prime \prime}\right|=\left[\int \beta_{i} P_{i}(L) P_{5}^{n_{i} / m_{i}}(L) F_{2}^{1 / m_{i}} l(T) d L\right]^{m}(2)
\end{aligned}
$$

$\mathrm{n}_{\mathrm{i}}, \mathrm{m}_{\mathrm{i}}, k_{\Delta v i}, \beta_{\Delta v i}, \mathrm{M}_{\mathrm{i}}$ is empirical parameters of the spectral transmission functions over the wave number spectrum $v$ :

$$
\begin{gathered}
\tau_{\Delta v}=\exp \left[-\sum_{i} \ln \tau_{\Delta v i}\right] \\
\mathrm{F}_{1}(\mathrm{~T}), \quad \mathrm{F}_{2}(\mathrm{~T}) \quad \text { is } \quad \text { temperature } \\
k_{\Delta v i} / k_{\Delta v 0}, \beta_{\Delta v i} / \beta_{\Delta v 0} . \\
\text { In relation }(2) \text { Pe - effective pressure: } \\
P_{\ni}=P_{N_{2}}+\sum_{k} B_{i k} P_{k}
\end{gathered}
$$

where $B_{i k}$ is the broadening factor of spectral lines for collisions of molecules $\mathrm{i}$ with molecule $\mathrm{k}$. For oxygen $B\left(\mathrm{O}_{2}\right)=0.8, B\left(\mathrm{CO}_{2}\right)=1.4 \div 1.6$. For water vapor $B\left(\mathrm{H}_{2} \mathrm{O}\right) \in|6.30|$ and is highly temperature dependent.

The parameter $\mathrm{M}$ determines the rate of transition of the spectral transmission functions from the weak absorption approximation to the strong absorption approximation. With overlapping spectral lines, Bouguer's law is fulfilled for the spectral transmission functions when $k_{\Delta v}(T)=\beta_{\Delta v}(T), \mathrm{m}=1, \mathrm{n}=0, \mathrm{M}=-1$. For bands with pressure-induced absorption and continuous absorption of radiation by the wings of the SLP $\mathrm{m}=\mathrm{n}=1, \mathrm{M}=-1, \quad k_{\Delta v}^{H}(T)=\beta_{\Delta v}$. For an arbitrary spectral transmission function $m \in\{0,1\}, n \in\{0,1\}, M \in\{0,-1\}$.

For a multicomponent inhomogeneous medium:

$$
\begin{gathered}
\left|\ln \tau_{i \Delta v}^{\prime}\right|=\int_{L} \kappa_{i \Delta v}(T) \rho[L(T)] d L, \\
\left|\ln \tau_{i \Delta v}^{\prime \prime}\right|=\left\{\int_{L} \beta_{i \Delta v}^{1 / m_{i}}(T) \rho_{i}[L(T)] P_{i \ni}^{n_{i} / m_{i}}(L) d L\right\}^{m_{i}} \\
\left|\ln \tau_{\Delta v}\right|=\sum_{i} \mid \ln \tau_{i \Delta v}[L(T)], \\
\tau_{\Delta v}=\exp \left[-\sum_{i} \ln \tau_{i \Delta \tau}[L(T)]\right] .
\end{gathered}
$$

The parameterization of the spectral transmission functions is determined for gaseous optically active ingredients broadened with nitrogen. The effect on the spectral transmission functions of the broadening of the SLP in collisions with the molecules of other components is taken into account by introducing an effective pressure.

$$
P_{i \ni}=P_{N_{2}}+\sum_{k} B_{i k}[L(T)] P_{k}(L),
$$

were

$B_{i k}=\alpha_{0 i}(i-k) / \alpha_{0 i}\left(i-N_{2}\right), \alpha_{0 i(}(i-k), \alpha_{0 i}\left(i-N_{2}\right)$ the half-widths of the lines for the collision of molecules $(i-k)$ and $\left(i-N_{2}\right)$, reduced to the pressure $\mathrm{P}=$ $1 \mathrm{~atm}$.

The dispersed phase of combustion products is taken into account in accordance with the experimental data [6] on the microstructure of the soot ash and its concentration. The parameters required for calculations (effective absorption, scattering, scattering indicatrix) are calculated in accordance with the microstructure of the soot sol and are used in the calculation schemes. An electronic library of optical characteristics of soot and mineral sols of various microstructures in the form of gamma distributions with modal radii $r_{m}$ from $r_{m}=0.003$ $\mu \mathrm{m}$ to $r_{\mathrm{m}}=10 \mu \mathrm{m}$ has been prepared for use in chamber furnaces when using coal.

When performing calculations of radiation heat transfer, a wide range of experimental studies was used, carried out on flame measuring complexes in the temperature range of $1500-2500 \mathrm{~K}$ and heated measuring complexes with electric heating [1-10]. As a result of these studies, the influence of non-equilibrium processes on radiation heat transfer was revealed [1-3], the radiation characteristics of water vapor in the spectral region 0.2-25 $\mu \mathrm{m}$ [11] were investigated, the spectral transmission functions and parameters of spectral lines were determined, and high-temperature atlases of the parameters of spectral lines of $\mathrm{CO}_{2}$ were prepared [12]. The environmental impact of atmospheric anthropogenic emissions is considered in [13-16, 18]. Numerical modeling of complex radiation heat transfer with the solution of the problem of the transfer of selective radiation from aerial carriers in the atmosphere is considered in $[17,22,23]$. In $[19,21]$, a mathematical model is considered for modeling radiation heat transfer taking into account the nonequilibrium and selectivity of radiation in the furnaces of boiler units. Thermodynamic and thermophysical properties of combustion products are calculated according to [20]. The processes of soot formation and soot burnout have been analyzed in [2426]. In recent years, significant progress has been achieved in the field of fine-structure spectrometry, including the components of combustion products of organic fuels and radiation heat transfer in structurally inhomogeneous multicomponent media, including hightemperature ones. For these purposes, electronic databases $[28,29]$ have been created at the level of international cooperation of various scientific groups with the inclusion of SLP parameters, including for $\mathrm{CO}_{2}$, $\mathrm{CO}, \mathrm{SO}_{2}, \mathrm{H}_{2} \mathrm{O}, \mathrm{OH}, \mathrm{NO}, \mathrm{NO}_{2}$ vapors. The possibility of their application for solving problems of radiation heat transfer for high-temperature media in combustion chambers of power units is to be determined in the future. 
The data on the numerical modeling of the spectral transmission functions by the parameters of spectral lines can be successfully used to obtain the parameters of the spectral transmission functions by approximate calculation methods: absorption band models, twoparameter method of equivalent mass. As an example, Fig. 1 shows the functions of the spectral transmission of $\mathrm{CO}_{2}$ in the spectral range of $450-1450 \mathrm{~cm}^{-1}$ for $P_{\mathrm{CO}_{2}}=1$ atm, $\mathrm{T}=300 \mathrm{~K}$ for various $\mathrm{CO}_{2}$ contents $\mathrm{W}$ from 0.03 to 3000000 atmo-cm.

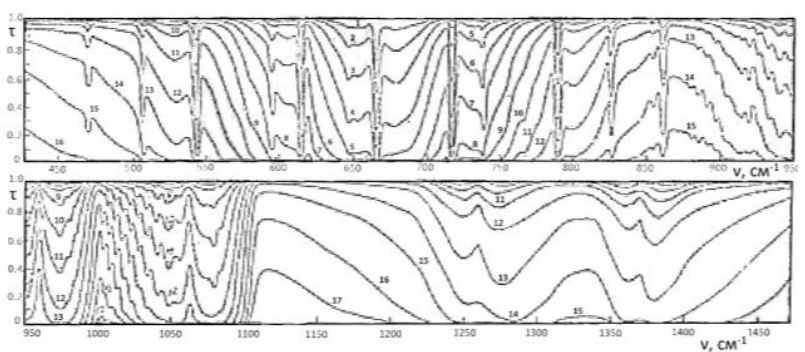

Fig. 1. Calculated by the method of numerical modeling (solid curves) and measured (points) absorption spectra of $\mathrm{CO}_{2}$ emission in the spectral range $450-1450 \mathrm{~cm}^{-1}$ for the content of $\mathrm{W}$, atm $\cdot \mathrm{cm}: 1-0.03 ; 2-0.1 ; 3-0.3 ; 4-1 ; 5-3 ; 6-10 ; 7-30 ; 8-100$; $10-1000 ; 11-5000 ; 12-10000 ; 13-30000 ; 14-100000 ; 15-$ 300000; 16-1000000; 17-3000000; $P_{\mathrm{CO}_{2}}=1 \mathrm{~atm}, \mathrm{~T}=300 \mathrm{~K}$.

Figure 2 illustrates the spectral absorption coefficients of $\mathrm{CO}$ and $\mathrm{NO}$, calculated from hightemperature atlases, the parameters of spectral lines for temperatures of $300,600,1200,1800,2500,3000 \mathrm{~K}$.
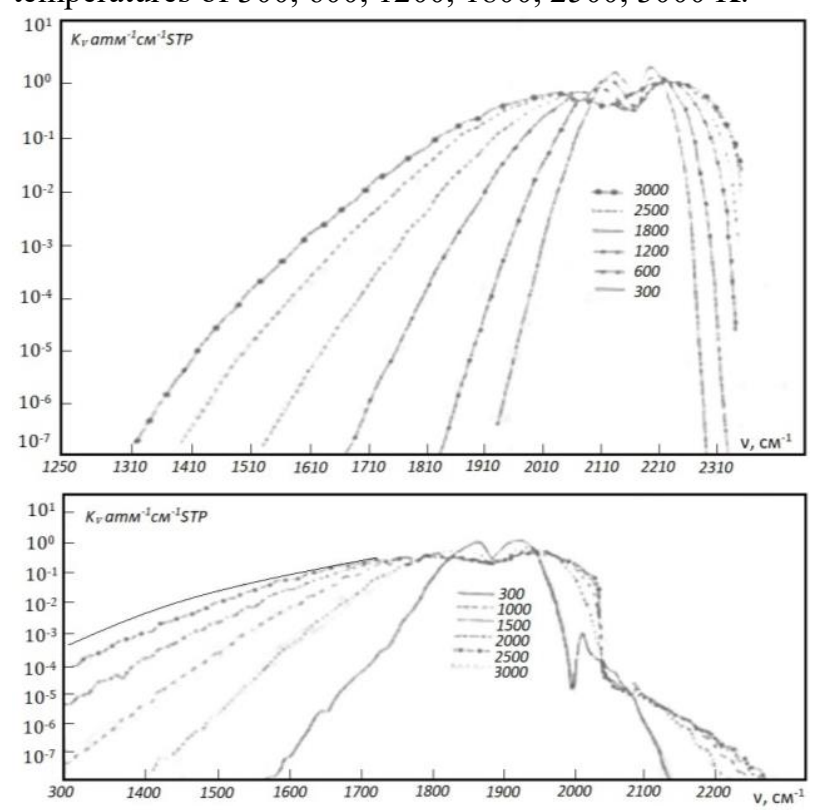

Fig. 2. The absorption coefficient in the main bands $4.67 \mu \mathrm{m}$ $\mathrm{CO}$ (a) and $4.54 \mu \mathrm{m} \mathrm{NO}$ (b) in the temperature range 300 $3000 \mathrm{~K}$.

Figure 3 shows the absorption spectra of $\mathrm{CO}$ at a $\mathrm{CO}$ content of 1 and 10 atmo-cm. at temperatures of 300 , 1200 , and $3000 \mathrm{~K}$ and the spectral transmission functions of $\mathrm{CO}$ in the range of $\mathrm{CO}$ contents along the optical path from 0.01 to 10000 atmo-cm at a temperature of $300 \mathrm{~K}$. An expansion of the main $\mathrm{CO}$ band with an increase in temperature is observed while maintaining the integral intensity of the $\mathrm{Si}(\mathrm{T})=$ const.
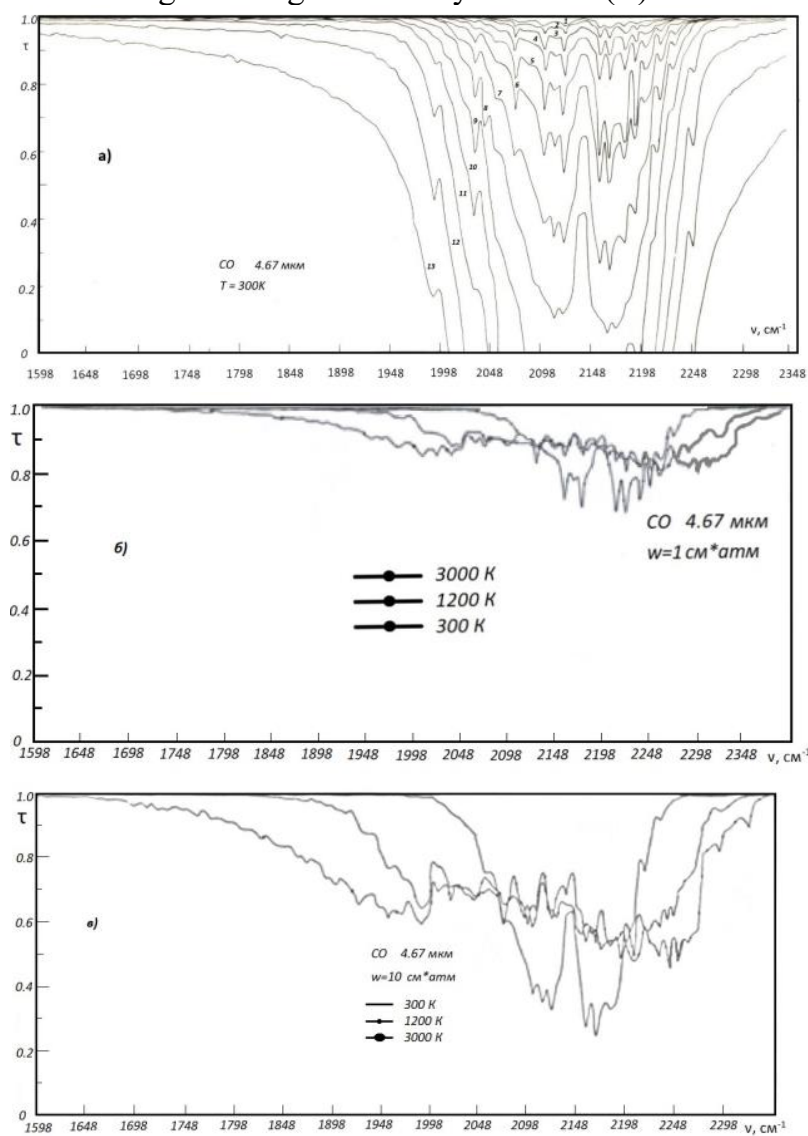

Fig. 3. Functions of the spectral transmission $\tau v$ of $\mathrm{CO}$ in the main band of $4.67 \mu \mathrm{m}$, calculated by the method of numerical modeling: a) for the content of $\mathrm{W} \mathrm{CO}$, atm $\cdot \mathrm{cm} ; 1-0.01 ; 2-$ $0.03 ; 3-0.1 ; 4-0.3 ; 5-1 ; 6-3 ; 7-10 ; 8-30 ; 9-100 ; 10-300 ; 11-$ $1000 ; 12-3000 ; 13-10000 ; b)$ for temperatures of 300,1200 , $3000 \mathrm{~K}$ at $\mathrm{W} \mathrm{CO}=1 \mathrm{~atm} \mathrm{~cm} \mathrm{STP}$; c) for temperatures of 300 , $1200,3000 \mathrm{~K}$ at $\mathrm{W} \mathrm{CO}=10 \mathrm{~atm} \mathrm{~cm} \mathrm{STP}$. Spectral resolution $\Delta v=10 \mathrm{~cm}^{-1}$.

\section{Closed modeling of radiation heat transfer in multi-chamber furnaces}

Currently, there are two possibilities for increasing the efficiency of radiation heat exchange in furnaces and increasing the steam output of boiler installations: increasing the number of burners in the furnace with the creation of strong radiation contrasts of individual flames against the general thermal background of combustion products in the furnace; the creation of multi-chamber furnaces, where an increase in the efficiency of radiation heat transfer is achieved by maintaining the dimensions of the combustion chamber of a multi-chamber design. The second option is more efficient and allows a wide variety of design solutions and allows the construction of steam boilers with natural and forced circulation, and also allows the use of mixed forms of circulation. Multi-chamber furnaces can be used for burning solid fuels. In this case, it is promising to use in boiler plants combustion of fuel in cyclonic prefurnaces, which allow cleaning the combustion products from the ash component of combustion products and 
slags. The combustion chamber itself in this case is actually a radiation heat exchanger, which is multichamber to increase the efficiency of radiation cooling of combustion products.

According to the mathematical model of radiation heat transfer developed by us, radiation cooling in the furnace is determined by the rate of radiation cooling $\partial \mathrm{T} / \partial \mathrm{t}$ (t-time) and the residence time of the combustion products in the furnace, so that the temperature at the furnace outlet is determined by the ratio:

$$
T_{\text {out }}=T_{a}-\int_{0}^{H} \frac{d T}{d t}(z) \frac{d z}{v(z)},
$$

where Ta is the adiabatic temperature of the combustion products, $\mathrm{v}(\mathrm{z})$ is the velocity of the combustion products; depending on the $\mathrm{z}$ coordinate with a change in temperature $T(z)$ in the direction of the combustion products. From relation (5) it follows that with an increase in the heat load of the furnace, the temperature at the outlet from the furnace increases. The greatest radiation cooling will be observed when using bottom burners that ensure the maximum residence time of the combustion products in the furnace. For a given height of the furnace and its dimensions, an increase in the boiler's steam production can be achieved by increasing the rate of radiation cooling $\partial \mathrm{T} / \partial \mathrm{t}$, which is achieved by reducing the cross-section of individual chambers in a multi-chamber furnace.

When solving problems of radiation heat transfer in heat units, we will operate with integral

$$
\begin{gathered}
J^{\uparrow \downarrow}\left(z_{0}, \theta_{0}, \varphi_{0}\right) \\
J^{\uparrow}\left(z_{0}, \theta_{0}, \varphi_{0}\right)=\int_{0}^{\infty} J_{\lambda}^{\uparrow}\left(z_{0}, \theta_{0}, \varphi_{0}\right) d \lambda, \\
J_{\downarrow}\left(z_{0}, \theta_{0}, \varphi_{0}\right)=\int_{0}^{\infty} J_{\lambda}^{\downarrow}\left(z_{0}, \theta_{0}, \varphi_{0}\right) d \lambda,
\end{gathered}
$$

where $J_{\lambda}^{\uparrow \downarrow}\left(z_{0}, \theta_{0}, \varphi_{0}\right)$ are the spectral intensities of thermal radiation, $z_{0}$ is the observation height, $\theta_{0}, \varphi_{0}$ are the zenith and azimuth angles of sight, respectively.

Having integrated $J^{\uparrow \downarrow}\left(z_{0}, \theta_{0}, \varphi_{0}\right)$ within the solid angle $2 \pi$, we obtain for the fluxes of thermal radiation the ratio

$$
J \uparrow \downarrow\left(z_{0}\right)=\int_{0}^{2 \pi} J^{\uparrow \downarrow}(z, \theta, \varphi) d \Omega,
$$

where $d \Omega$ is the solid angle element. The rate of radiation cooling $d T / d t$ is determined by the ratio:

$$
\frac{\partial T(z, \theta, \varphi)}{\partial t}=\frac{1}{\rho(z, \theta, \varphi) C_{p}(z, \theta, \varphi)} \cdot \frac{\partial F(z, \theta, \varphi)}{\partial z},
$$

where $\rho(z, \theta, \varphi), C_{p}(z, \theta, \varphi)$ are the density and heat capacity, respectively, at a local point with coordinates $z, \theta, \varphi$. Denote:

$$
F(z, \theta, \varphi)=F^{\uparrow}(z, \theta, \varphi)-F^{\downarrow}(z, \theta, \varphi),
$$

Radiation cooling is most efficiently manifested in the torch core, and therefore its temperature is $15-20 \%$ lower than the adiabatic one. This means that during the combustion of the fuel the torch cools down considerably as a result of radiation cooling. These results are confirmed by theoretical calculations performed according to the developed mathematical model, which takes into account the effect of nonequilibrium processes on radiation heat transfer.

For the formation of a short flame, it is advisable to use multi-row burners, where the supply of air and fuel alternates and is carried out through capillary tubes mounted in a matrix type burner.
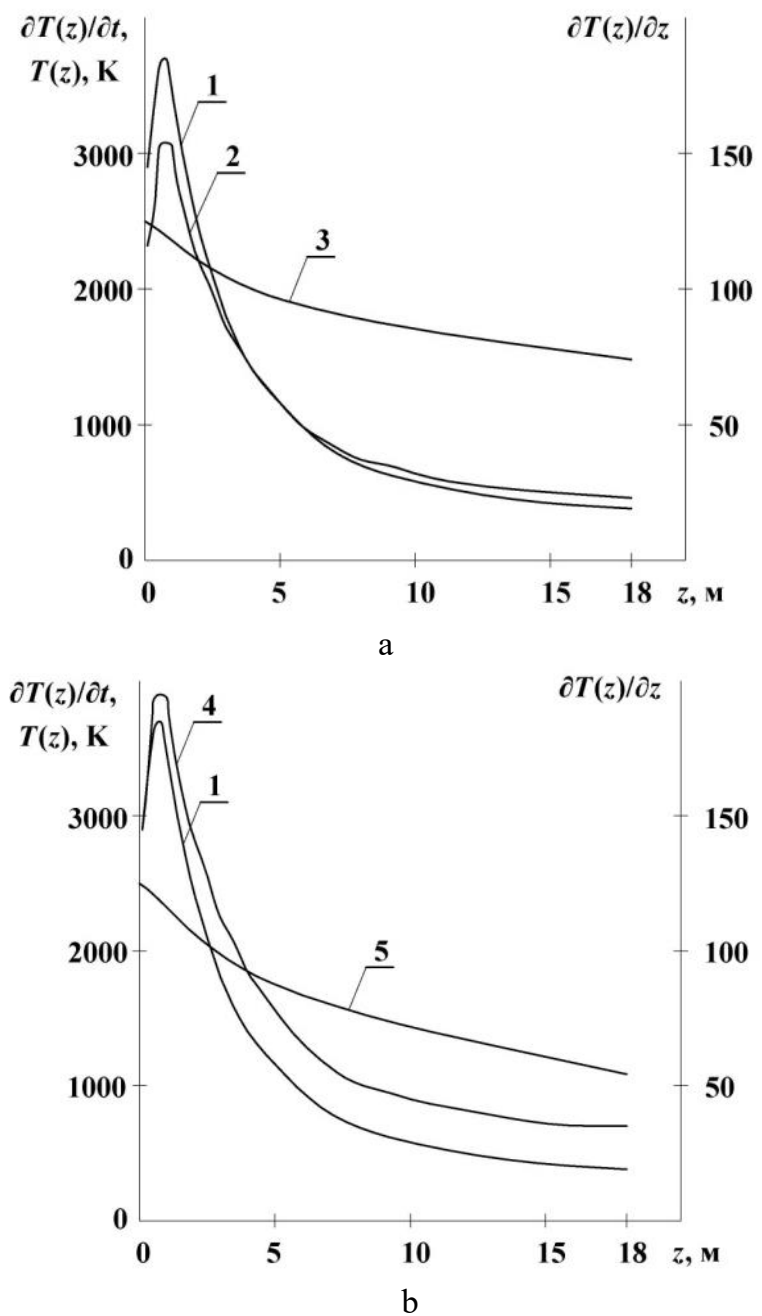

Fig. 4. The results of calculating radiation heat transfer in a multi-chamber furnace with a horizontal section of a cell of $1.25 \times 1.6 \mathrm{~m}^{2}$ for an initial average flow rate of combustion products of $25 \mathrm{~m} / \mathrm{s}$ (a) and $20 \mathrm{~m} / \mathrm{s}$ (b) $\partial T(z) / \partial t, \partial T(z) / \partial z$ is the rate of radiation cooling, $\mathrm{T}(\mathrm{z})$ - temperature profile of the cross-section average temperature depending on the height $\mathrm{z}$ above the sections of the capillaries of the multi-row burner. 1 -

$\partial T(z) / \partial t, 2-\partial T(z) / \partial z$ for the initial average velocity of the flow of combustion products $25 \mathrm{~m} / \mathrm{s} ; 3-\mathrm{T}$ (z) for the initial average velocity of the flow of combustion products $25 \mathrm{~m} / \mathrm{s} ; 4$ -

$\partial T(z) / \partial z$ for the initial average velocity of the flow of combustion products $20 \mathrm{~m} / \mathrm{s} ; 5-\mathrm{T}(\mathrm{z})$ for the initial average velocity of the flow of combustion products $20 \mathrm{~m} / \mathrm{s}$. 
In fig. 4 shows examples of calculations of the vertical profiles of the rates of radiation cooling $d T(z) / d t, d T(z) / d z$, from the height $Z$ above the cuts of the capillaries of the matrix burner. Fuel - natural gas, the size of the horizontal section of the multi-chamber furnace cell is $1.25 * 1.6 \mathrm{~m}^{2}$. The velocity of the combustion products in the initial section is $25 \mathrm{~m} / \mathrm{s}$ and $20 \mathrm{~m} / \mathrm{s}$ at a pressure in the furnace of $1 * 10^{5} \mathrm{~Pa}$, the height of the flame zone is $\Delta z=0.7 \mathrm{~m}$. The calculations take into account the equilibrium and nonequilibrium radiation cooling. It is assumed that the combustion process of various ingredients of gaseous fuel occurs independently at the optimum value of the excess air coefficient $\alpha=1.03$. Volumetric coefficients of attenuation, absorption and scattering are normalized to the measured values of the optical density of the sol [13].

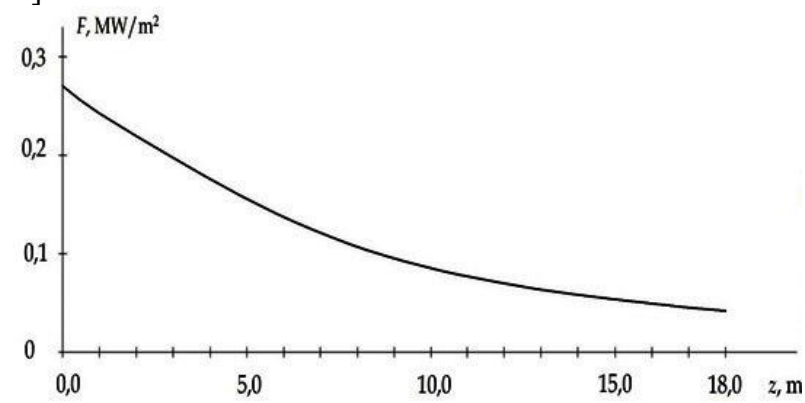

Fig. 5. Distribution of the integral radiation flux depending on the height in the combustion chamber in the case of weak absorption

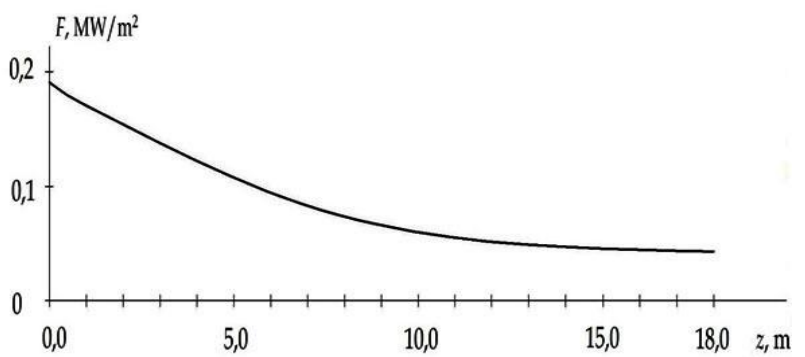

Fig. 6. Distribution of the integral radiation flux depending on the height in the combustion chamber, calculated using the spectral transmission function by the two-parameter method of equivalent masses

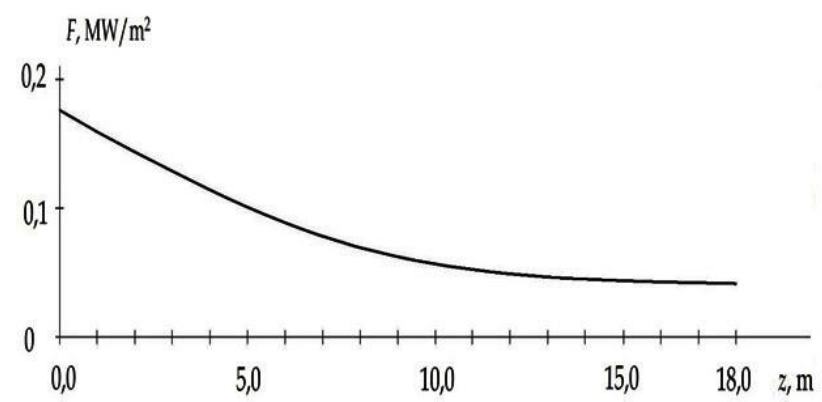

Fig. 7. Distribution of the integral radiation flux depending on the height in the combustion chamber, calculated without taking into account the effective pressure

In Figures 5-7 show the distribution of the integral flux $F(z)$ depending on the height in the combustion chamber, calculated using the spectral transmission functions by the two-parameter method of equivalent masses and the "weak absorption" approximation

With the advent of supercomputers, it becomes possible to use numerical methods for solving radiation transfer problems [9]. Their use is limited by insufficient reliability of information on the parameters of the spectral lines of the gas components of combustion products at high temperatures, which are realized in the combustion chambers of power units.

When performing calculations of radiation heat transfer, a two-parameter method of equivalent mass was used when calculating the spectral intensities of thermal radiation $[1,4,6-9]$.

The highest radiation load is observed in the lower part of the furnace and on the matrix multi-row burner device, which is performed with water cooling along an independent circulation loop.

For solid fuel furnaces, calculations were performed with cyclonic furnaces. The calculations are carried out taking into account the soot dispersed phase [27] whose contribution to the radiative heat transfer is significant.

Combustion of finely crushed solid fuel in cyclone pre-furnaces will allow the most efficient collection of ash within the pre-furnace. Figure 5 shows a functional diagram of a multi-chamber furnace cell with cyclonic pre-furnaces. Each cell of a multi-chamber furnace has two cyclonic pre-furnaces. The number of cells determines the overall capacity of the boiler plant. It is assumed that the counter-flow of combustion products from the pre-furnaces into the working chamber, which in this case is a heat exchanger. Swirling counterflows of combustion products break up and fill the chamber. The tangential speed of the flow is sharply reduced, and the kinetic energy of the flow is converted into heat. Further, there is radiation heat exchange in the chamber during the flow of fuel combustion products and the transfer of radiation energy to the heat-perceiving pipe surfaces.

Table 1 shows the temperature $\mathrm{T}(\mathrm{z})$ depending on the height $\mathrm{z}$ in the combustion chamber; radiation cooling rate $d T(z) / d t, \mathrm{~K} / \mathrm{s}$; flow velocity $\mathrm{V}(\mathrm{z}), \mathrm{m} / \mathrm{s}$; rate of temperature change from height $\mathrm{z} \frac{d T}{d z}, \mathrm{~K} / \mathrm{m}$. In table $1 \frac{d T}{d z}=\frac{\Delta T}{\Delta z}, V(z)=V_{0} \frac{T(z)}{T_{0}(z)}$.

Table 1

\begin{tabular}{|c|c|c|c|c|}
\hline $\begin{array}{l}\mathrm{z}, \\
\mathrm{m}\end{array}$ & $\mathrm{T}(\mathrm{z}), \mathrm{K}$ & $d T(z) / d t, \mathrm{~K} / \mathrm{s}$ & $\begin{array}{l}\mathrm{V}(\mathrm{z}), \\
\mathrm{m} / \mathrm{s}\end{array}$ & $\frac{d T}{d z}, \mathrm{~K} / \mathrm{m}$ \\
\hline 0 & 1940 & 1960 & 14 & \\
\hline 1 & 1800 & 1820 & 13 & 140 \\
\hline 2 & 1720 & 1380 & 12,41 & 80 \\
\hline 3 & 1665 & 885 & 12 & 55 \\
\hline 4 & 1615 & 638 & 11,6 & 50 \\
\hline 5 & 1570 & 568 & 11,3 & 45 \\
\hline 6 & 1525 & 436 & 10,89 & 45 \\
\hline
\end{tabular}




\begin{tabular}{|c|c|c|c|c|}
\hline 7 & 1480 & 374 & 10,68 & 40 \\
\hline 8 & 1440 & 354 & 10,48 & 40 \\
\hline 9 & 1405 & 331 & 10,21 & 35 \\
\hline 10 & 1370 & 310 & 9,95 & 35 \\
\hline 11 & 1340 & 292 & 9,74 & 30 \\
\hline 12 & 1310 & 286 & 9,53 & 30 \\
\hline 13 & 1285 & 234 & 9,35 & 25 \\
\hline 14 & 1260 & 229 & 9,16 & 25 \\
\hline 15 & 1235 & 224 & 8,98 & 25 \\
\hline 16 & 1210 & 220 & 8,80 & 25 \\
\hline 17 & 1190 & 189 & 8,66 & 20 \\
\hline 18 & 1170 & 170 & 8,51 & 20 \\
\hline 19 & 1150 & 167 & 8,37 & 20 \\
\hline 20 & 1130 & 164 & 8,23 & 20 \\
\hline
\end{tabular}

Kuznetsk sludge of the following chemical composition in the working mass is used as fuel: $\mathrm{C}_{\mathrm{H}_{2} \mathrm{O}}=$ $26.5 \%, \mathrm{C}_{\text {sol }}=10.2 \%, \mathrm{C}_{\mathrm{C}}=54.39 \%, \mathrm{C}_{\mathrm{H}}=3.9 \%, \mathrm{C}_{\mathrm{S}}=$ $0.5 \%, \mathrm{C}_{\mathrm{N}}=1.6 \%$. The design efficiency of the boiler is $91 \%$, the temperature of the superheated steam is $\mathrm{T}_{\mathrm{oh}}=$ $560{ }^{0} \mathrm{C}$, the excess air coefficient is $\alpha=1.08$, the temperature of the steam-water mixture at the inlet is $\mathrm{T}_{0}$ $=215{ }^{0} \mathrm{C}$, the pressure is $\mathrm{P}_{\mathrm{oh}}=13.9 \mathrm{MPa}$. For a boiler with a steam capacity of $\mathrm{D}=210 \mathrm{t} / \mathrm{h}$, the corresponding fuel supply is $B=5 \mathrm{~kg} / \mathrm{s}$. For a multi-chamber furnace of four cells and eight pre-furnaces, $0.625 \mathrm{~kg} / \mathrm{s}$ of coal is burned in each pre-furnace. At a fuel feed rate in the prefurnace of $100 \mathrm{~m} / \mathrm{s}$, the radius of the pre-furnace is $\mathrm{r}=$ $0.32 \mathrm{~m}$. For a boiler with a steam capacity of $\mathrm{D}=420$ $\mathrm{t} / \mathrm{h}$, the radius of the pre-furnace is $0.45 \mathrm{~m} / \mathrm{s}$.

The volumes of combustion products were calculated in the following order: their mass was calculated from the concentrations of the burning components, then the mass of oxygen for their combustion was calculated. The oxygen concentration is used to determine the volume of air, taking into account that the concentration $\mathrm{C}\left(\mathrm{O}_{2}\right)=$ $21 \%$.

The cross section of the cell of the radiation heat exchanger is determined by the initial temperature of the combustion products and the initial velocity of the combustion products, the fuel efficiency of the prefurnaces. For example, for a boiler with a capacity of $210 \mathrm{t} / \mathrm{h}$, the cell size in the horizontal section is $1.6 \times 6 \mathrm{~m}^{2}$ if the number of cells is four.

The data on the temperature profile $T(z)$ and the chemical composition of combustion products are used to calculate the radiation flux of combustion products onto heat-sensing surfaces (screens).

Cyclonic furnaces with liquid slag removal have a number of advantages over conventional furnaces. Their main advantage is the high density of heat release, which leads to a decrease in the boiler dimensions. The high degree of ash removal from the fuel up to $90 \%$ makes it possible to intensify the operation of convective heating surfaces and increase the time of continuous operation of the radiant steam superheater, and reduce slagging. The use of coarse dust allows to reduce the cost of fuel

preparation. Their main disadvantages include difficulties in burning fuels with a low level of volatile and high-moisture fuels, increased consumption of electricity for blast, and increased heat loss with slag.

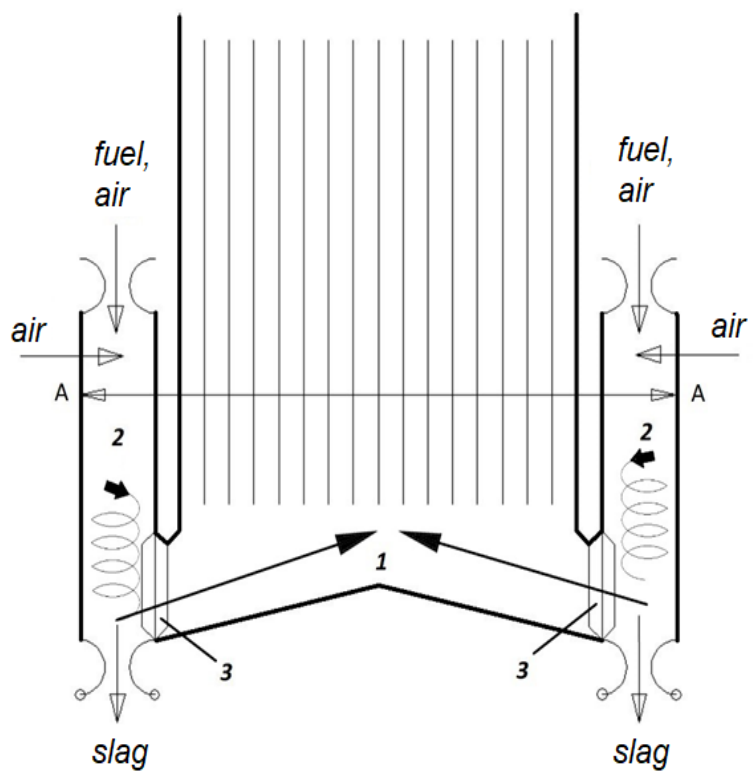

Fig. 8. Functional diagram of a cell of a multi-chamber furnace for solid fuel: 1 - heat exchanger; 2 - cyclonic furnaces; 3 - ash catcher.

In fig. 8 shows the temperature dependences $\mathrm{T}(\mathrm{z})$ for the initial velocities of the outflow of combustion products $\mathrm{V}_{0}: 14 \mathrm{~m} / \mathrm{s}, 21 \mathrm{~m} / \mathrm{s}, 28 \mathrm{~m} / \mathrm{s}$ in a multichamber furnace cell with a horizontal section of $1.6 \times 6$ $\mathrm{m}^{2}$.

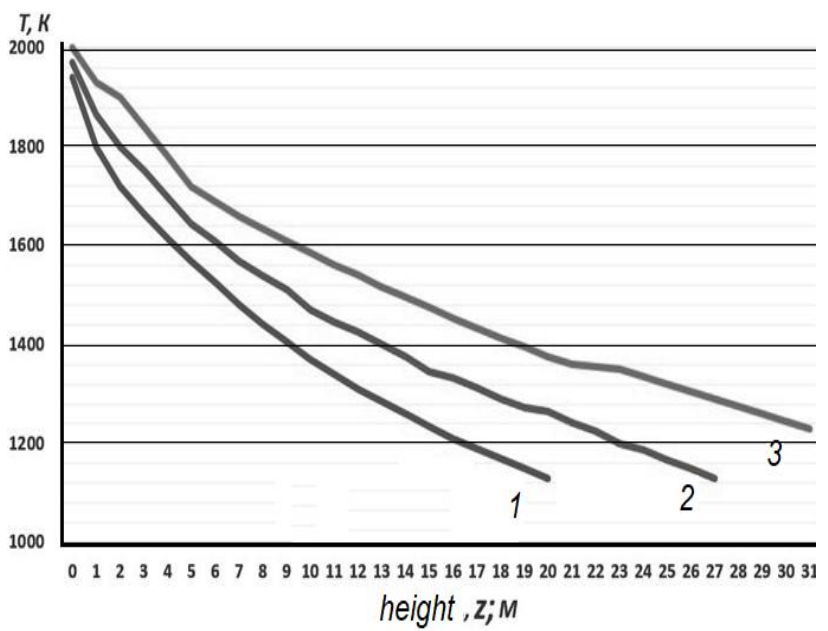

Fig. 9. Dependences of temperature $T(z)$ for the initial velocity of the outflow of combustion products $\mathrm{V}_{0}(\mathrm{z}), \mathrm{m} / \mathrm{s}$ : 1$14 ; 2-21 ; 3-28$.

\section{Conclusions}

In conclusion, let us dwell on the main results obtained in this work.

A method has been developed for modeling the transfer of thermal radiation in a multicomponent atmosphere that is inhomogeneous in structural 
characteristics of the furnace space. Designs of multichamber furnaces with an upward movement of combustion products and vertical development of the flame of hearths, multi-row, forming a single matrixtype burner for all chambers of a multi-chamber furnace with a common gas manifold for supplying fuel and a collector for supplying an oxidizer (air or oxygen) are proposed. The burner device is expediently made with a radiator for cooling it with water along an independent circulation circuit. The design of a multi-chamber furnace when using gas fuel makes it possible to increase the efficiency by $2-3 \%$ and increase its productivity by 2-3 times while maintaining the steam parameters and boiler dimensions.

A closed simulation of radiation heat exchange in the combustion chamber of a multi-chamber furnace with a horizontal cell section of $1.25 \times 1.6 \mathrm{~m}^{2}$ and $1.4 \times 1.4 \mathrm{~m}^{2}$ with an excess air factor $\alpha=1.03$ and an average initial velocity of combustion products of $25 \mathrm{~m} / \mathrm{s}$ and $20 \mathrm{~m} / \mathrm{s}$ has been performed. Information on the velocities of the radiation cooling $\frac{d T}{d t}, \frac{d T}{d z}$, and temperature profile $\mathrm{T}$ ( $\mathrm{z}$ ) depending on the height $\mathrm{z}$ above the cuts of the capillaries of the matrix burner. Calculations of heat perception on heat-absorbing surfaces of the combustion chamber are performed. The total flux $\mathrm{F}$ of thermal radiation on the furnace surface agrees with the change in enthalpy at the furnace outlet with an error of $0.3 \%$. Nonequilibrium radiation cooling is $7.5 \%$. Taking into account the effective pressure in the furnace leads to an increase in the total radiation flux $\mathrm{F}$ by $5 \div 6 \%$.

For boilers of a multi-chamber design operating on solid fuel, it is advisable to use a design with cyclonic pre-furnaces that create counterflows of combustion products. The working chamber in this case is a heat exchanger with tube heat-absorbing surfaces, with an upward flow of combustion products.

\section{References}

1. Moskalenko N.I., Mirumyants S.O., Loktev N.F., Misbakhov R.Sh. Kazan KGEU edition, p.260 (2014)

2. Moskalenko N.I., Zaripov A.V., Ilin Yu.A. Russian Physics Journal 53, №2, pp.107-113 (2010)

3. Moskalenko N.I., Zaripov A.V., Loctev N.F., Parzhin S.N., Zagidullin R.A. Intechweb, Croatia, Optoelectronics - devises and applications, pp. 469-526 (2011)

4. Moskalenko N.I., Ilin Yu.A., Kayumova G.V. Journal of Applied Spectroscopy, 56, № 1, pp.122-127 (1992)

5. Moskalenko N.I., Ilin Yu.A., Sadykova M.S. Izv. vuzov. Physics, 57, № 9, pp. 3-9 (2014)

6. Moskalenko N.I., Safiullina Ya.S., Zagidullin R.A. Izv. Vuzov, Problems of Energetics, № 5-6, pp. 23-32, (2013)

7. Moskalenko N.I., Mirumyants S.O., Parzhin S.N., Dodov I.R. Journal of Applied Spectroscopy, 83, № 3, pp. 449-453 (2016)
8. Moskalenko N.I., Mirumyants S.O., Parzhin S.N., Dodov I.R. Journal of Applied Spectroscopy, 83, № 5, pp. 832-836 (2016)

9. Moskalenko N.I., Ilin Yu.A., Sadykova M.S. Russian Physics Journal, 57, pp. 1153-1158 (2015)

10. Moskalenko N.I., Zaripov A.V., Loktev N.F., Ilyin Yu.A. Journal of Applied Spectroscopy, 77, № 3, pp. 378-385 (2010)

11. Moskalenko N.I., Zaripov A.V., Loktev N.F., Parzhin N.S., Zagidullin R.A. Intechweb, Croatia, pp. 469-526 (2010)

12. Moskalenko N.I., Zotov O.V., Ilin Yu.A., Russian Physics Journal, 59, №12, pp. 2017-2021 (2017)

13. Moskalenko N.I., Misbakhov R.Sh., Bagautdinov I.Z., Loktev N.F., Dodov I.R. Aeronautics, 59, №3, pp. 419-425(2016)

14. Moskalenko N.I., Sadykova M.S., Safiullina Ya.S. Izv. Vuzov, Problems of Energetics, № 3-4, pp. 28-37, (2014)

15. Moskalenko N.I., Khamidullina M.S., Safiullina Ya.S. Izv. Vuzov, Problems of Energetics, № 7-8, pp. 312, (2014)

16. Moskalenko N.I., Khamidullina M.S., Safiullina Ya.S. Izv. Vuzov, Problems of Energetics, № 9-10, pp. 21-30, (2014)

17. Moskalenko N.I., Rodionov L.V., Khamidullina M.S., Afanasyev I.A. Izv. Vuzov, Problems of Energetics, № 1-2, pp. 33-43, (2015)

18. Moskalenko N.I., Dodov I.R., Loktev N.F. Problems gas-dynamics and heat-mass-exchange in energetics installation, Moscow, Izd. MEI, pp. 229-232 (2015)

19. Moskalenko N.I., Zagidullin R.A., Zaripov A.V., Loktev N.F. Izv. Vuzov, Problems of Energetics, № 1-2, pp. 23-33, (2012)

20. Alemasov V.E., Dregalin A.F., Tishin A.P. and other Mathematical modeling of high-temperature processes in power plants, Moscow, VINITI edition, p. 254 (1972)

21. Alemasov V.E. Thermodynamically and thermophysical properties of combustion products, Moscow, VINITI edition, p. 490 (1972)

22. Moskalenko N.I., Sadykova M.S. NCE-2014, KGEU edition, 3, pp. 262-272 (2014)

23. Afanasiev I.A., Moskalenko N.I., Bagautdinov I.Z. NCE-2014, KGEU edition, 3, pp. 52-59 (2014)

24. Bakirov F.G., Zakharov V.M., Polishchuk I.Z., Shaikhutdinov Z.G. Poformation and over combustion of soot at burning of hydrocarbon fuels. Moscow, Machinebuilding edition, p.128 (1989)

25. Levterov A.M., Levterova L.I. Vistnik NTU, №5, pp. 130-141 (2013)

26. Marig Matti, Journal of Aerosol Science, 38 iss.2, pp. 141-156 (2007)

27. Vasileva O.V., Ksenofontov S.I., Krasnova A.G., Kokshina A.V. Alternative of Energetics and Ecology, № 19, pp. 101-111 (2015)

28. Rothman L.S. et al. Journ. Quant. Spectr. Radiat. Transfer., 130, pp. 4-50 (2013)

29. Gordon I.E. et al. Journ. Quant. Spectr. Radiat. Transfer, 203, pp. 3-69 (2005) 